Research Paper

\title{
Living with water \\ How memory and experience can help build community resilience in Dordrecht
}

Theresa Audrey O. ESTEBAN, Erasmus University Rotterdam, Graduate School of Social Science and the Humanities; The Philippines

\begin{abstract}
In 2021, Dordrecht, the oldest city in the Netherlands, will be commemorating the 600 th anniversary of the St. Elizabeth flood. This disaster flood event inundated the entire Dordrecht and separated the city from Geertruidenberg. After the flood Dordrecht was left with only the old city center that the city had to reclaim their land. To date Dordrecht has remained an island surrounded by water. The city's vulnerability to flooding have prompted the city to actively participate in climate adaptation strategies and innovative design methodologies to help the island city cope with changing climatic conditions. Dordrecht is one of the cities participating in the Room for the River project which allows vast tracks of land to be flooded in the event of a big flood. The city is also surrounded by dikes that protect parts of the city from any impending flood danger. Still the historic city center which lies in the unembanked area occasionally experience flooding. Every two to five years residents of Dordrecht especially in the old city center experience some low level flooding due to high waters and heavy rainfall. Yearly the city conducts a drill in the city center to train people on how to place flood barriers and sandbags in front of their homes. However, there is also a sense of complacency especially for the areas in the city where the structural measures were heavily constructed (those that are within the dike). This feeling of complacency may have been placed due to their strong belief that the city is indeed safe due to the structural measures that have been carefully integrated to ensure that flooding will never happen again.

Memory-based disaster experience can be the starting point in building knowledge on disasters. Most often people who have experienced a disaster can provide experiential knowledge in dealing with disasters in the future. Further people who experience disasters on a more regular basis have more built in memory and knowledge. Using interviews from key stakeholders of Dordrecht, the paper will draw out how this memory-based disaster experience and living with water helps Dordrecht towards its vision to become a self-reliant island.
\end{abstract}

\section{Keywords}

Resilience, Collective engagement, Collective engagement urban resilience framework, Memory-based disaster experience, Netherlands 


\section{Introduction}

The profound impact of the Sint Elizabeth flood is apparent in Dutch history. The Rijks Museum holds a piece of beautifully painted depiction of the Sint Elizabeth flood in four panels which "serve as a powerful illustration of the traditional narrative describing the fight against floods that shaped Dutch national identity" (van Asperen, 2019: 36). History, including the artistic representation of the flood disaster, impacted the collective memory of the Dutch that many understood the Sint Elizabeth flood as an apocalyptic event most especially in Dordrecht.

The impact of the flood in Dordrecht was huge that it wiped out 17 villages (Waals, et al., 2011) and separated Dordrecht from Geertruidenberg. Land was slowly reclaimed after the big flood through compartments where each compartment is protected by dikes (Waals, et al., 2011). Centuries of land reclamation and diking in Dordrecht have shaped the city into what it is now, an island city that lies between the Rhine and Meuse two large and important rivers not just in the Netherlands but the entire Europe.
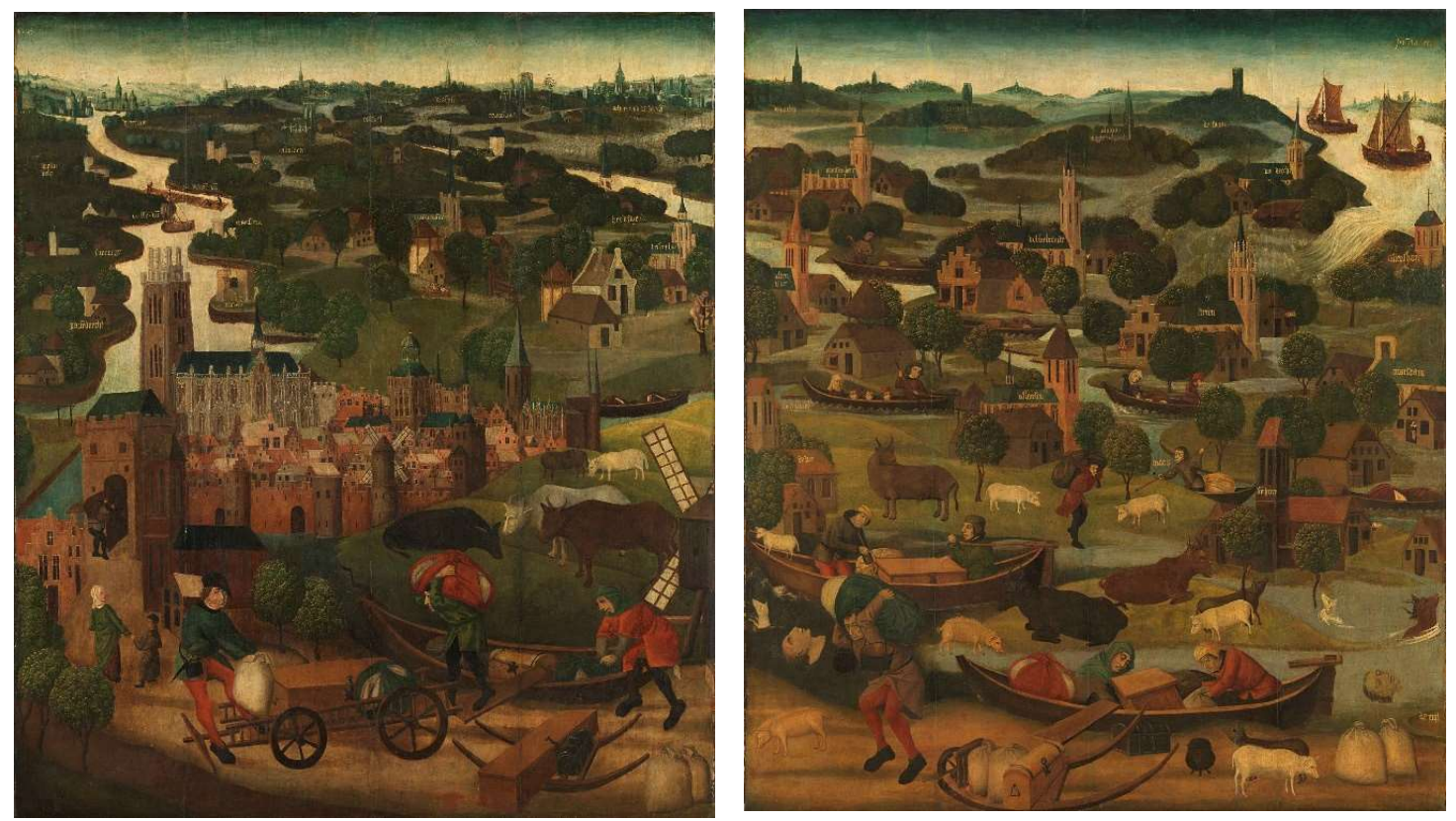

Figure 1 The Saint Elizabeth's Day Flood 1490 by Master of the St Elizabeth Panels (Source: https://useum.org)

While the Sint Elizabeth flood was the biggest flood that made an impact on the physical and economic landscape of Dordrecht, the 1953 Great North Sea flood made a pivotal role in constructing a long-term flood preventive measure in the entire country through technology and engineering. The hardest hit area in the Netherlands was Zeeland where water levels reached NAP +4.55 (Rijkswaterstraat, 2019) still Dordrecht was not spared as water level reached NAP +3.70 (Hinborch, 2011) and inundated the city specifically the historic city center. In 1993 and 1995 extreme river discharge from the Meuse caused flooding in Zuid Holland. Also, in 1995 the threat of a flood event due to problems in the Rhine resulted to an evacuation of 200,000 people for a week (Jak and Kok, 2000). These flood events have resulted to not just preventive measures but adaptation measures such as the Room for the River project that allows vast tracks of land to be flooded in the event of a flood. 
The City of Dordrecht like many other cities in the Netherlands are divided between the binnen de dijk (within the dike) and buiten de dijk (outside the dike). As a result of the compartmentalization, a large part of the island is binnen de dijk, while the historic city center, the area of the Staart, the inland seaport, and the green area near Hollands Diep and Nieuwe Merwede are buiten de dijk. Every two to five years Dordrecht residents most especially those living in the historic city center experience low level flooding due to high waters coming from the river. Such many of the residents in the unembanked areas are aware of the risks and vulnerabilities they are facing. For those in the embanked areas the residents rarely experience such flooding that the notion of risks and vulnerabilities is low.

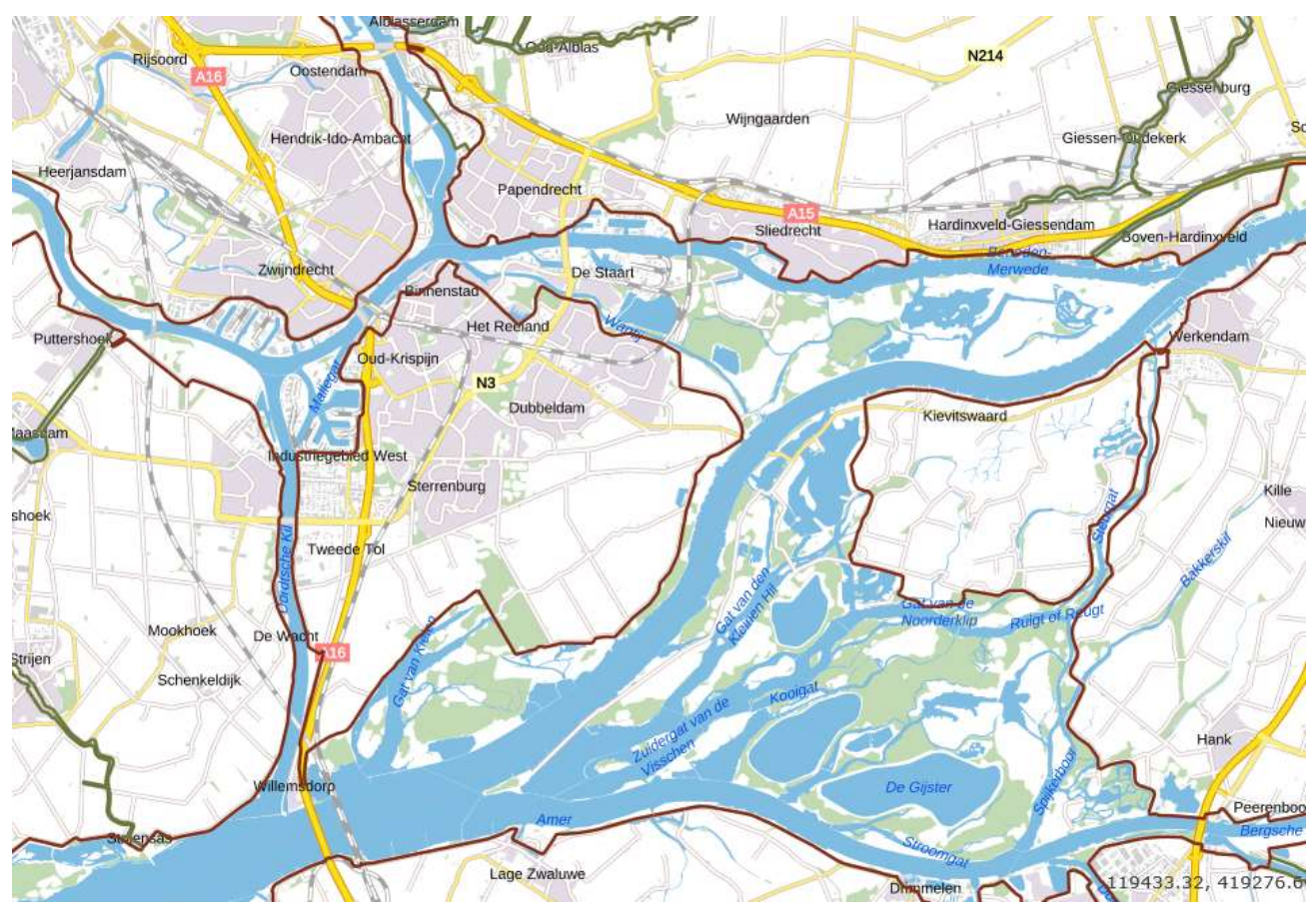

Figure 2 Map of Dordrecht showing the embanked and unembanked areas (Source: Risicokaart.nl)

This paper focuses on memory-based disaster experience which is one of the thematic areas being investigated in the author's dissertation research 'Collective engagement: from disaster-prone city to disaster-resilient city'. Disaster experience provide some experiential knowledge in dealing with future disasters. Most often people who experience disasters on a regular basis have more built in memory and knowledge. Using interviews from key stakeholders of Dordrecht, the paper will draw out how this memory-based disaster experience and living with water helps Dordrecht towards its vision to become a self-reliant island. The paper proceeds with a discussion on memory-based disaster experience and how this can be the starting point in building community resilience. Thereafter, the empirical study will be presented with a brief discussion on the methodology. Finally, the analysis and conclusions will be discussed. 


\section{Memory-based disaster experience and resilience building}

Cities are complex socio-ecological systems that grow in different pathways and timescales. The path to resilience is a dynamic process that goes through several dimensions. There is no one size fits all strategy in building resilience. The city's complexity in terms of not just the physical attributes but also social and cultural attributes require different approaches. One thing remains the same for most cities, in a disaster context experience results in a steep learning curve for the community, the government and many other city stakeholders to adapt to the situation. Hooli (2016) found that 'those who regarded themselves better prepared are those who have experienced and learned what the floods are like' (p. 702).

Memory-based disaster experience allows those who experience it to develop coping strategies (Pfister, 2011). This does not usually mean though that the learning is sustained through a long period. Pfister (2011) pointed out that a "disaster gap, the rare occurrence of severe hazards during almost a century, is a significant element in explaining the loss of functional disaster memory" (p. 17). Nevertheless, memory-based disaster experience play a significant role for groups, communities, cities and even nations to develop not just coping mechanisms but disaster mitigating infrastructures to ensure their safety and security. The Netherlands is a good example on this having ensured that the 1953 Great North Sea flood will never happen again, the Dutch implemented the Deltaworks project in 1958. The continuing research and improvements on water management and climate change adaptation showcase the stronghold of that flood memory.

Memory and learning are important in building resilience. In fact, the panarchy framework, an expanded concept of resilience, use the terms 'revolt' and 'remember' period to illustrate the adaptive cycles present in socio-ecological systems (Gunderson and Holling, 2002; Berkes, et al., 2008). The 'revolt' period causes the critical change (such as a disaster) while the 'remember' period "facilitates renewal and reorganization by drawing on the memory that has been accumulated" (Berkes, et al., 2008: 18). Specifically, Folke (2006) referred to memory as the "accumulated experience and history of the system, and it provides context and sources for renewal, recombination, innovation, novelty and self-organization following disturbance" (p. 259). Interestingly, the word "accumulated" is used in both context which means that it is a growing experience that builds capacity to renew and reorganize. Cook (2018) seconds this by presenting "collective memory as the accumulation of individual recollections" and "shared public memory becomes a dynamic force that shapes and transforms the narrative of what is remembered" (p. 329). If flooding incidents repeat overtime the chances of retaining memory and learning from it increases. But of course a flooding disaster is not something that many desire to happen in order for the city and its stakeholders to learn.

Trainings, narratives, and information that is widely disseminated to the general population help retain learnings derived from the experience. Repetition of these types of knowledge building activities and information reinforce awareness. A well-informed and aware 
stakeholders helps the city in building urban resilience because it lessens the surprise a disturbance such as a disaster would bring. It increases their adaptive capacity.

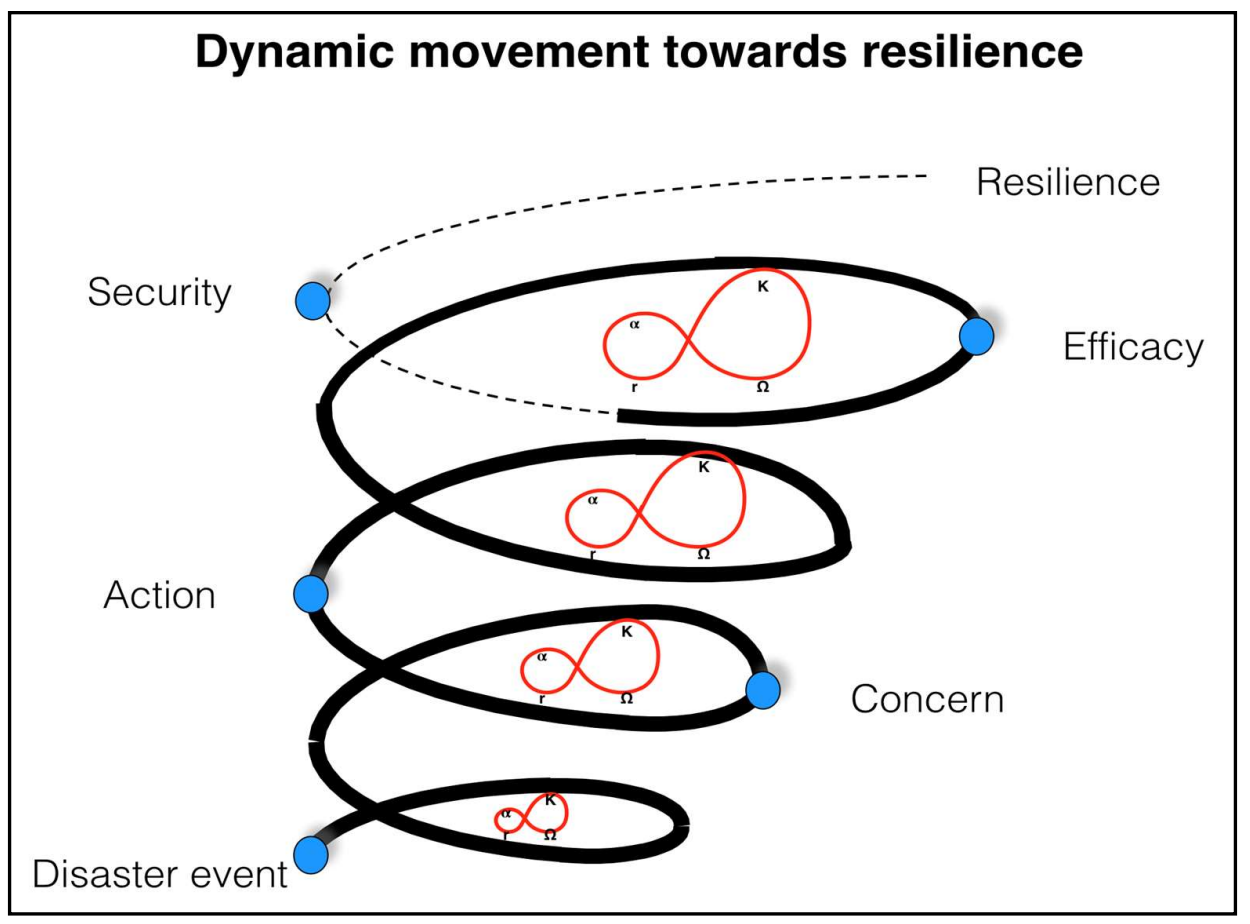

Figure 3 Dynamic movement towards resilience from the disaster event (Source: Esteban, 2018)

Esteban (2018) illustrated in Figure 3 that a disaster event, whether this was a recent or distant past experience, provoke city stakeholders to behave or act on this experience to improve their situation. In order for cities to build resilience cities go through a dynamic process of change through several dimensions (Esteban, 2018). Resilience is not the end of the process rather it should be understood as a continuous process of maintaining a level of stability. These dimensions follow an adaptive cycle of stability and change within the collective engagement urban resilience framework (Figure 4). The framework has two approaches in building urban resilience, the government and the self-organization approaches. Both approaches start from a collective concern where institutional and non-institutional stakeholders remember and learn from past disaster events. Stakeholders in this dimension have a shared vision and concern in building urban resilience. Collective action facilitates the exchange of information, knowledge and experiences to help in creating solutions (Esteban, 2018). Collective efficacy is the point where stakeholders with their knowledge strengthened by the exchange of information and experiences in their various networks actively engage. The last dimension is collective security, which can be seen in Figure 4 converges back to concern. Collective security is the dimension where stakeholders reach a high level of awareness. This means that the stakeholders are equipped with the knowledge and information on risks and vulnerabilities as well as how to prepare and act once a disaster happens. 


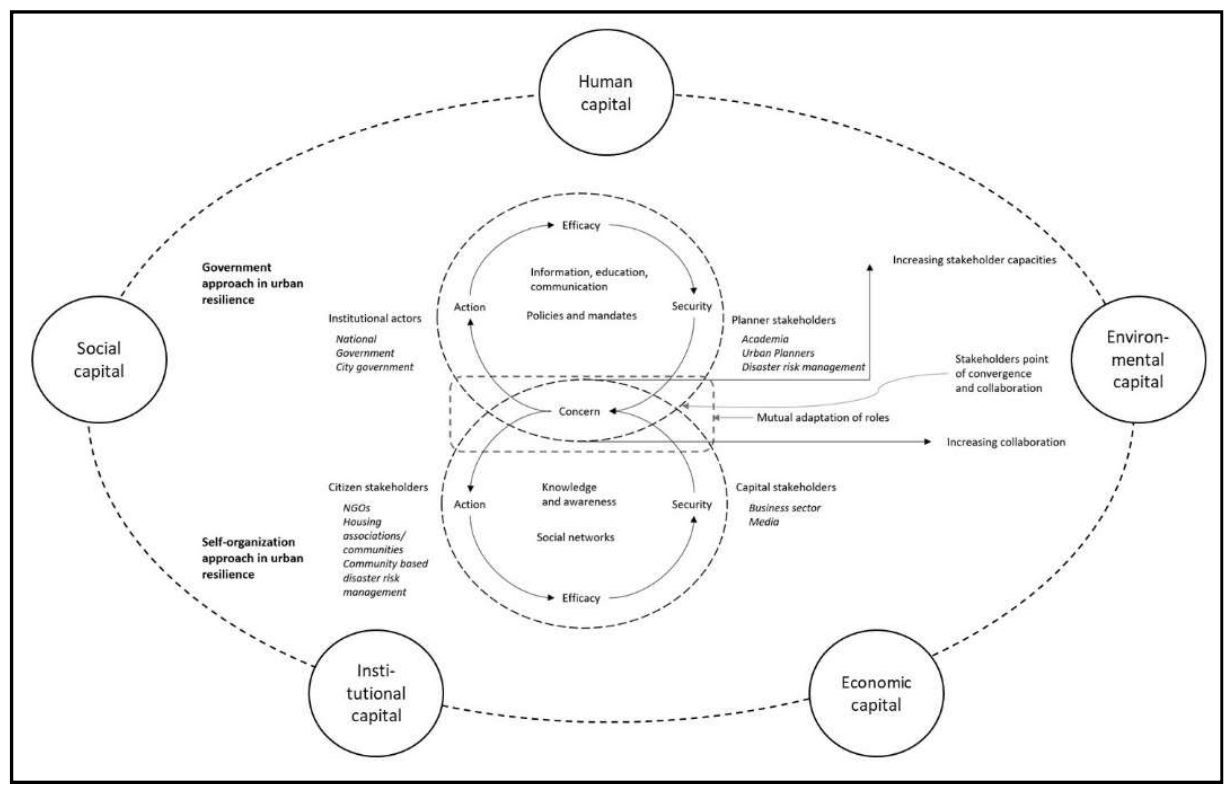

Figure 4 Collective engagement urban resilience framework (Source: Esteban, 2018)

How a city progress from one dimension to another depends on the domains of change that leads to its transformation state. Figure 5 shows the domains of change within the collective engagement urban resilience framework which influence the dynamic movement to urban resilience. Stakeholders are part of the domains of change and are in fact critical in the formation of either a formal or informal organization that can be the bridge between the government approach and the self-organization approach towards urban resilience. The bridge within this domain of change facilitate the translation of issues affecting the city as a whole into opportunities for change and renewal. This bridge is similar to the bridging social capital which is the inter-relationship with other groups and stakeholders within the city (Esteban, 2017). Strong social capital helps in establishing 'trust and reciprocity within and between networks' of stakeholders and actors (Esteban, 2017: 223). 


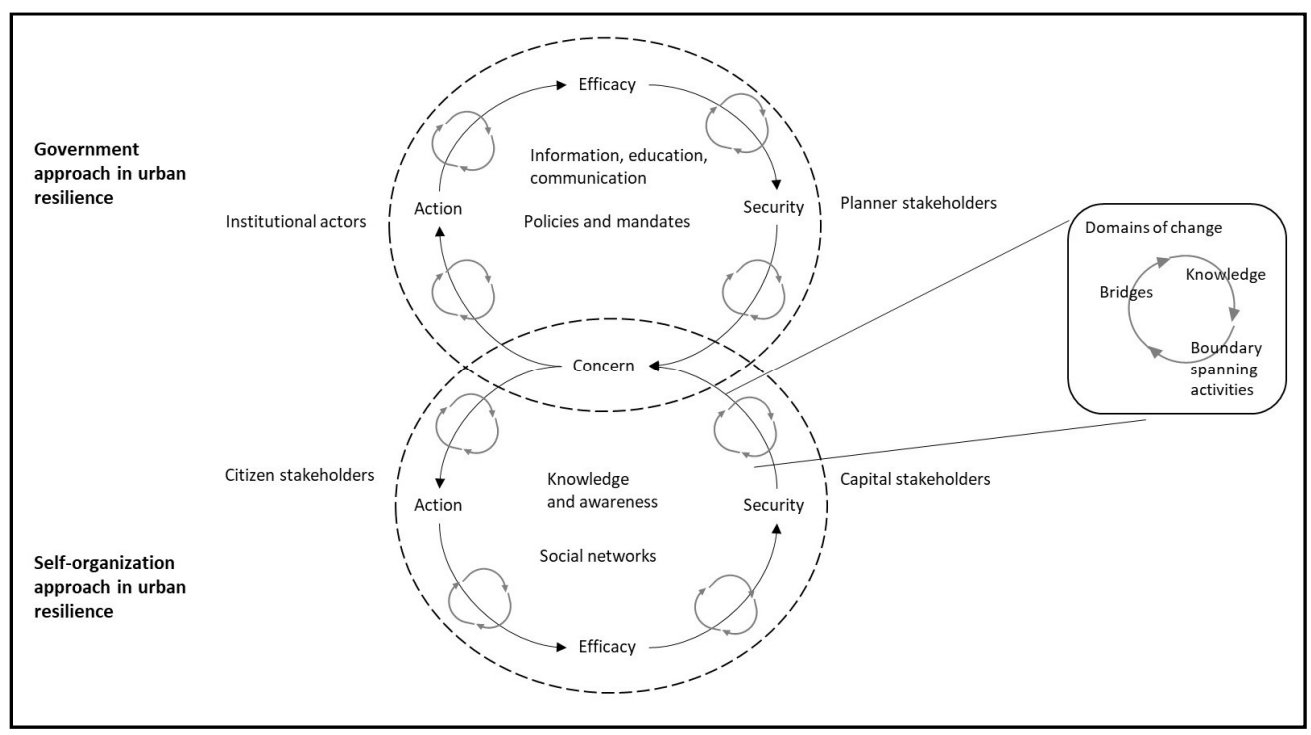

Figure 5 The domains of change within the collective engagement urban resilience framework (Source: Esteban, 2018)

\section{Empirical study: living with water in Dordrecht}

The paper used a qualitative approach through face-to-face interviews of key informants. Following the collective engagement urban resilience framework the key informants come from the institutional actors, planners stakeholders, citizen stakeholders and capital stakeholders. An initial list of three targeted informants were interviewed. Succeeding interviewees came recommended by the initial list creating a snowball until 15 interviewees were reached. The interviews were carried out by the author from November 2018 to February 2019 and forms part of the dissertation research. The questions asked during the interview ranged from the disaster experience, collaboration with stakeholders, awareness and concern, disaster risk management, resilience and resilient city. In this paper the objective is to draw out the memory-based disaster experience of the stakeholders in the City of Dordrecht and assess the level of awareness on the risks and vulnerabilities in living with water between areas in the city that are frequently flooded and those that rarely experience this. For that matter, the results of the interview on questions particular to disaster experience and awareness and concern is considered. This is also because there is a current limitation in the time for coding and analyzing all aspects of the interviews. However, this paper forms an important contribution to the overall analysis for the Dordrecht case in the dissertation project.

The qualitative data derived from the interviews were transcribed and processed using the Atlasti software. For the thematic areas disaster experience and awareness and concern a total of 14 themes emerged from the interviews. These were further coded using the three domains of change, bridges, knowledge and boundary spanning activities. A separate code memory-based disaster experience was used to draw out salient points on this specific topic. The findings presented below will begin with the memory-based disaster experience, followed by each domains of change. 


\subsection{Memory-based disaster experience}

There is a collective memory on how Dordrecht was shaped by the 1421 Sint Elizabeth flood among the interviewees. The 1421 Sint Elizabeth flood "drowned 17 villages roughly in the hinterland" (Institutional stakeholder, male) and changed the entire landscape of Dordrecht. There was "a very large inland sea, then the island was gradually reclaimed from that sea" (Planner stakeholder, male) making "Dordrecht an island which is still is today" (Institutional stakeholder, male). The Sint Elizabeth flood affected the economic situation of Dordrecht that one interviewee even said, "if that flood would not have happened Dordrecht would probably be the Amsterdam of the Netherlands" (Institutional stakeholder, male).

The other big flood that the interviewees remember is the 1953 Great North Sea flood. However, interviewees noted that while the 1953 flood was a big flooding disaster for the country, in Dordrecht the effect was not as big. Interviewees noted that it was the province of Zeeland that was gravely affected and that it was the dike ring opposite of Dordrecht that got flooded (Institutional stakeholder, male (2); Planner stakeholder, male). The interviewees noted a minor flooding in the city center but acknowledge that the 1953 flood have had an impact on the collective memory of the country. Interviewees recalled that the national government vowed that the flood of 1953 should never happen again which resulted to how the Dutch deal with flood risk management through the Deltaworks project.

Interviewees recalled that the 1993 and 1995 riverine threat changed the water management strategy of the Dutch from responding to a disaster through preventive measures to adapting to disasters (Institutional stakeholder, male; Planner stakeholder, male). However, interviewees shared that since the 1953 Great North Sea flood no other disasters have happened in Dordrecht or in the country that in general people feel safe. Interviewees mentioned that flooding has been calculated to happen 1 in 10,000 years that people translate this to "not going to happen" and they have other "more urgent calamities to worry about so it is not in their priority" (Institutional stakeholder, male; Planner stakeholder, male). An institutional stakeholder interviewee opined that, "Perhaps some say we have done it too well because they don't see any risk anymore. . . The attention is fading and fading away. That's what happened in the Netherlands." (Institutional stakeholder, male). This is supported by the statement of another interviewee, "We are in Holland we feel so safe and well-protected. We don't have the experience of a real flood, only in ' 53 but there are not so many people that are really experiencing that. What other disaster have we faced not so many. So we don't have the experience and we don't know what will overcome us when it really happens, we don't know." The previous institutional stakeholder interviewee also pointed out that the older generation know about the 1953 flood because they experienced it. He said that the older generation are more concerned to the point that they will call the waterschap to check if the water pumps are working because they don't hear the pumps anymore.

\subsection{Bridges}

There are a lot of public organizations in Dordrecht that are interested in the city. The city government itself make efforts in making people more conscious of the risk of water (Planner stakeholder, male). Three of the planner stakeholder interviewees all come from academic institutions who have themselves done a number of studies on Dordrecht that range from technical engineering to social science related studies on public participation and governance.

Interviewees named the veiligsheidsregio (safety region) in Dordrecht as an organization that work together with the waterschap (waterboards) to improve awareness in the city on flood 
risk. The national government and Dordrecht "as a city itself are working on awareness" (Institutional stakeholder, male). Institutional stakeholder interviewees noted the communication strategies that they conduct to the general population. An interviewee noted that awareness is improving in Dordrecht but also admit that there are still no studies on awareness or on what level of awareness the population has (Institutional stakeholder, male; Planner stakeholder, male).

\subsection{Knowledge}

The interviewees asserted that the people in general are not concerned about flooding since they trust the government and the flooding disaster happened long ago. But the interviewees also noted that the people in Dordrecht are more conscious of the flood risk than elsewhere in the Netherlands because people see the water bodies (Planner stakeholder, male (2); Planner stakeholder, female; Institutional stakeholder, male). One interviewee said that Dodrecht is "one of the few cities, especially the old town [that] is more or less in the river . . .you see some of the houses [ ] standing [on] the river so from centuries it is quite normal to live with the water" (Institutional stakeholder, male). He asserted that this has allowed them to adapt to changing water conditions and that this is not new to them.

Interviewees mostly refer to people living buiten de dijk as more aware compared to those living binnen de dijk because "they have regular elevated levels on the quays ... the awareness there is bigger than behind the embankments" (Planner stakeholder, male). Comparing this to the people living within the dike rings an interviewee remarked "People inside the dike rings, they say 'a disaster will occur once in every ten thousand years, well it will not happen today and it will not happen tomorrow, but maybe several hundred years,' so it is much harder to make them aware that the situation can be tomorrow," (Institutional stakeholder, male). According to the interviewee this mindset makes it harder to communicate to people living within the dike to invest in their house in case of a flood because people will say "then make strong dikes and make sure that it will not happen" (Institutional stakeholder, male).

The higher level of awareness of people living buiten de dijk can also be attributed to the amount of information that is given to them. Yearly the people receive letters on high water levels and remind them on what to do in case of high water levels. One interviewee remarked, "I think that around the big rivers there is a lot of educational workshops and teaching moments for the citizens to be aware of what is happening and the government is really helping and making sure that every citizen actually knows about it," (Planner stakeholder, female).

\subsection{Boundary spanning activities}

There are ways to communicate flood risks one is through the website overstroming.nl however one institutional stakeholder interviewee shared that not a lot of people are aware of this. He said that even his colleague did not know about the website. Media (television and newspapers) and social media (Facebook) have been used to increase the communication and awareness among all stakeholders but interviewees also mentioned that it is really difficult to measure if these medium really reach the people (Institutional stakeholder, male (2)). One interviewee mentioned the TV series "Als de dijken breken" that actually brought "the consciousness on why we should evacuate" (Citizen stakeholder, male). The same interviewee also pointed out that after that show ". . two days later everyone forgot it. Goes back to normal life. And did anything change after this series? No. Apparently not." 
In Dordrecht there is a yearly exercise where people in the old city center put vloedschotten (flood barriers) in front of their houses (Institutional stakeholder, male (2)). This is an exercise that the City of Dordrecht do together with the waterschap (Institutional stakeholder, male). There were also some exercise on how to evacuate within your house. Interviewees see the yearly vloedschotten exercise as a good way to make people aware of the flood risk and also to prepare themselves. Candidly an interviewee mentioned that, "It is a very good thing that there is a high water situation every two years because if it is once every thousand years people won't believe it or they will say it will not happen in my time," (Institutional stakeholder, male). The same interviewee opined that "there is a correlation with the last [experience], the period between the two flooding and the awareness." He made the example of the high water level they experienced in 2012 and 2013 where people 'reacted more accurately' in 2013 because with the flood in 2012 'it was 8 years ago [from] the last flooding.' He also shared that the city government have also made instruction films on how to use the flood barriers and the sandbags.

Interviewees shared that there are a lot of activities being done in Dordrecht to improve the awareness of people (Institutional stakeholder, male; Planner stakeholder, male). These activities are also being done together with other cities and even in schools. One of the more successful projects they have done in Dordrecht are the experimental projects on floating houses. "Experiments are rather a safe place to do different things but when you start working with each other for quite a while you get to know each other and know why, what their responsibilities are, what their problems are and when you know their problems and responsibilities you can make it also your own and combine it with your own urban development," (Institutional stakeholder, male). The interviewee see this as a way to keep the people's relationships and each others interests to make an integrated plan. Another interviewee mentioned that they plan to commemorate the Sint Elizabeth flood in 2021 by doing a number of activities every year until that time (Planner stakeholder, male). He said that there are two main things that they will do to make people more aware of rainfall flooding, one is to have open garden days in spring to showcase how they have 'greened their gardens'. The other is an open attic evening in autumn 'where people invite each other to their attic and they have a dinner there and play a game [ ] with the neighbors'. He further explained that the latter is 'to raise awareness about sheltering, that they have to [make a] shelter in their attic.'

\section{Analysis: collective memory in Dordrecht}

Results of the interviews reveal a collective memory on the flooding disasters that happened in Dordrecht and in the Netherlands. Much of these collective memory can be attributed to the ever present narratives depicted in art works and the landscape of Dordrecht which serve as a constant reminder on how the city was formed. There is a level of consciousness on flood risk that is present in Dordrecht with the fact that the city is an island surrounded by water. There is also a regular occurrence of high water levels in the old historic city center. While the 1953 Great North Sea flood did not have a big effect on Dordrecht its occurrence and the result thereafter (the implementation of the Deltaworks project) is in the collective memory of the Dutch in general.

It can be said that both the Sint Elizabeth and North Sea flooding disasters resulted to the natural movement of people to protect themselves from any impending danger. After the Sint 
Elizabeth flood people reclaimed land from the sea to rebuild Dordrecht, and after the North Sea flood the Dutch vowed the flood disaster will never happen again by strengthening existing dikes, constructing flood barriers, among others. Through these engineering feats the Dutch have ensured the security of the population which as one interviewee has said "we have done it too well because they don't see any risk anymore." It is common knowledge for the people in the Netherlands that it is 'safe and well-protected' from floods. While these two flooding disasters are well within the collective memory, the disaster gap is wide that the level of awareness and concern for any flood risk is fading.

From the interviews it is quite apparent that Dordrecht is actively engaging with different stakeholders. The City of Dordrecht work closely with the veiligsheidsregio and waterschap on various activities in relation to prevention from as well as preparation for disasters. As formal bridges to city stakeholders the boundary spanning activities they conduct, such as the yearly vloedschotten exercise in the old historic city center, equips the residents with knowledge as well as a reminder on what can happen and how one should prepare for flooding. Yet, it can be noted in the interviews that the level of awareness on flood risk is stronger among people living buiten de dijk because of these regular exercises. Also, there is regular information on high water levels communicated to the residents in these areas. Such that even if with the glaring presence of the water in Dordrecht and the collective memory of the flooding disasters one cannot say that the risk of flooding is within the collective consciousness of all the people.

Dordrecht is working towards their vision to be a "self-reliant island" and improving the awareness of the people is an important facet of this. Quoting one institutional stakeholder interviewee, "The philosophy [is] zelfredzaam, self-reliant island, and that vision is still valid it's a bit undermined by the recent intervention but I think that vision to be self-reliant is I think a promising way." Planned activities specified in the interviews to increase awareness on flood risk, climate adaptation, and flood preparation is supported by planners and institutional stakeholders. This paves the way for opportunities to learn, remember, discuss, and experience that in turn will help in the transformation of Dordrecht into becoming zelfredzaam.

\section{Conclusion: Three watermarks}

Memory-based disaster experience. Memory-based disaster experience can help stir a shared experience to work towards a shared vision. History has shown that after the 1421 Sint Elizabeth flood and 1953 Great North Sea flood physical measures were done to secure the population from flood risk. In this case, the experience have left an indelible watermark on the manner of response the Dutch has with regards to flood risk - "never to happen again." While the narratives and the collective memory is still present the disaster gap that has emanated due to the strong preventive measures of the Deltaworks project after the 1953 flood have caused flood risk awareness to wane.

Living with water. The regularity of the high water levels and flood risk management activities buiten de dijk residents are trained and equipped with knowledge. This places them in line with the City of Dordrecht's vision to become a self-reliant island. Activities such as the proposed commemoration of the 600th Sint Elizabeth flood anniversary will help remind people of the rich history of the city as well as an opportunity to showcase projects such as the Room for the River which can be considered a high watermark on innovative climate change adaptation strategy. 
Collective memory. Halbwachs (1980) differentiated collective memory from history by stating that collective memory "is a current of continuous thought whose continuity is not at all artificial, for it retains from the past only what still lives or is capable of living in the consciousness of the groups keeping the memory alive." Therefore, if the rest of the population of Dordrecht binnen de dijk continue to have a distant attitude towards flood risk then commemorations, remembrance, communication and information will remain a watermark visible only when held towards the light.

\section{Acknowledgements}

I would like to thank the interviewees from the City of Dordrecht for their willingness to be interviewed and their honesty in sharing their views. I am especially thankful to my PhD promotor Dr. Jurian Edelenbos of the Erasmus University Rotterdam who has supported me from the beginning of my PhD journey, provided extensive feedback on my dissertation project, and continues to guide me in the direction that would most help me succeed. I also would like to thank my colleagues Gerjan and Petra for candidly sharing with me their "flood memory" knowledge and childhood learnings one morning as I disturbed them in their office. Hoping they will not get tired of me talking about floods and disasters.

\section{References}

Berkes, Fikret; Colding, Johan; Folke, Carl (2008) Navigating social-ecological systems: Building resilience for complexity and change, Cambridge: Cambridge University Press

Cook, Margaret (2018) "“It Will Never Happen Again": The myth of flood immunity in Brisbane", Journal of Australian Studies, Vol. 42, No. 3 (August)

Esteban, Theresa Audrey O. (2018) Building resilience through collective engagement, paper presented at the conference Constructing an urban future: The sustainability and resilience of cities, Abu Dhabi, United Arab Emirates, March 18-19, 2018 edn.

Esteban, Theresa Audrey O. (2017) "Collective engagement: picking up after the storm" in Urban governance in the realm of complexity, eds. M.P. van Dijk, J. Edelenbos \& K. van Rooijen, United Kingdom: Practical Action Publishing Ltd.

Folke, Carl (2006) "Resilience: The emergence of a perspective for social-ecological systems analyses", Global Environmental Change, Vol. 16, No. 3 (August)

Gunderson, Lance H.; Holling, Crawford Stanley (2002) Panarchy: understanding transformations in human and natural systems, USA: Island Press

Halbwachs, Maurice (1980) The collective memory, New York: Harper \& Row

Hinborch, Milan (2011) Flood defence town centre Dordrecht, Master's Thesis edn, Delft, The Netherlands: Delft University of Technology

Hooli, Lauri Johannes (2016) "Resilience of the poorest: coping strategies and indigenous knowledge of living with the floods in Northern Namibia", Regional Environmental Change, Vol. 16, No. 3 (March) 
Jak, Martine; Kok, Matthijs (2000) "A database of historical flood events in the Netherlands" in Flood issues in contemporary water management, eds. Marsalek J., Watt W.E., Zeman E. \& Sieker F., Dordrecht, The Netherlands: Springer

Nederhand, José; Bekkers, Victor; Voorberg, William (2014) Self-Organization and the Role of Government: How and why does self-organization evolve in the shadow of hierarchy? Rotterdam, The Netherlands: Erasmus University Rotterdam

Pfister, Christian (2011) "The monster swallows you" RCC Perspectives, No. 1 (January)

Rijkswaterstaat (2019) The flood of 1953. Available:

https://www.rijkswaterstaat.nl/english/water/water-safety/the-flood-of1953/index.aspx

Risicokaart (2019) Risicokaart.nl. Available: https://www.risicokaart.nl/

Useum.org (2019) Master of the St. Elizabeth panels. Available: https://useum.org/artist/Master-of-the-St-Elizabeth-Panels

Van Asperen, Hanneke (2019) "Charity after the Flood", The Rijksmuseum Bulletin, Vol. 67, No. 1 (January-March)

Waals, Hans; Kelder, ETG; Van Os, Nico; Van Herk, Sebastiaan (2011) Working apart together-filling the water safety gap. In Submitted to 5th International Conference on Flood Management, Japan. 